\section{In vivo measurement of colonic butyrate metabolism in patients with quiescent ulcerative colitis}

\author{
E J Simpson, M A S Chapman, J Dawson, D Berry, I A Macdonald, A Cole
}

School of Biomedical Science, Nottingham University, UK

E J Simpson

I A Macdonald

School of Clinical

Sciences

M A S Chapman

D Berry

A Cole

School of Biological Sciences

J Dawson

Correspondence to: Dr M A S Chapman, Department of Colorectal Surgery, Good Hope Hospital, Rectory Road, Sutton Coldfield B75 7RR, UK.

Accepted for publication 21 July 1999

\begin{abstract}
Background-Butyrate, a short chain fatty acid produced by bacterial fermentation, is a major fuel source for the colonocyte. In vitro work has shown that ulcerative colitis may be characterised by a metabolic defect in colonocyte butyrate oxidation.

Aims-To investigate the rate of metabolism of rectally administered butyrate in patients with quiescent colitis.

Methods- $\left[1-{ }^{13} \mathrm{C}\right]$-butyrate enemas were administered to 11 patients with long standing quiescent ulcerative colitis and to 10 control patients. The rate of production of ${ }^{13} \mathrm{CO}_{2}$ in exhaled breath over four hours was measured by isotope ratio mass spectrometry combined with indirect calorimetry in order to measure $\mathrm{CO}_{2}$ production. This allowed calculation of the patients' resting energy expenditure and respiratory quotient.

Results-Over a four hour period, 325 (SEM 21) $\mu \mathrm{mol}{ }^{13} \mathrm{CO}_{2}$ was recovered in breath samples from the colitis group compared with 322 (17) $\mu \mathrm{mol}$ from the control group (NS). The respiratory quotient of the colitic group was significantly lower than that of the control group. Conclusion-There was no difference in the rate of metabolism of butyrate between the two groups. It is unlikely that there is a primary metabolic defect of butyrate metabolism in patients with quiescent ulcerative colitis.

(Gut 2000;46:73-77)
\end{abstract}

Keywords: ulcerative colitis; in vivo butyrate metabolism

Short chain fatty acids (SCFAs) are produced in the human large bowel by fermentation of non-starch polysaccharides (dietary fibre) by the colonic bacteria. ${ }^{1}$ Acetate, propionate, and butyrate are the major SCFAs produced by this process and much interest has focused on the importance of butyrate in cell metabolism. Butyrate is the major fuel source for the colonic epithelium (colonocyte) ${ }^{2}$ and is necessary for salt and water absorption by the colonic mucosa. ${ }^{3}$ A lack of butyrate can result in inflammation, as seen in diversion colitis. This has been satisfactorily treated in one study by increasing luminal butyrate levels via enema administration. ${ }^{4}$

Ulcerative colitis is a mucosal disease of the large bowel predominantly affecting the left colon. This part of the large bowel has a greater dependence on butyrate as a fuel source than the right colon. ${ }^{5}$ Colonocytes harvested from patients with fulminant ulcerative colitis show an impaired ability to oxidise butyrate ${ }^{6}$ which gave rise to the hypothesis that colitis was characterised by an energy deficiency, leading to cell death and chronic inflammation. An animal model, resembling the inflammation seen in colitis, has been produced by blocking mitochondrial $\beta$ oxidation of butyrate. ${ }^{7}$ Chapman et al confirmed this finding using mucosal biopsy specimens from patients with quiescent colitis. ${ }^{8}$ Furthermore, metabolic abnormalities have been found in the terminal ileum of patients with colitis, suggesting that a failure of butyrate metabolism may be a systemic defect. ${ }^{9}$ Inflammation only occurs in the large bowel mucosa as it is the only site where butyrate is a major fuel source. Others, however, have been unable to reproduce these results, despite using similar techniques..$^{10} 11$

In spite of these conflicting findings, groups have administered SCFA enemas to patients with colitis, ${ }^{12-14}$ in the hope that exogenous SCFA solutions may reduce the inflammation and symptoms. Early results have been promising, as assessed by decreased mucosal inflammation using endoscopic, histological, and clinical criteria, although large double blind trials have not been performed. ${ }^{15}$

It has been suggested that butyrate enemas may alleviate the symptoms of colitis by restoring luminal levels of butyrate to normal; supraphysiological concentrations may also be able to overcome the partial metabolic block of butyrate metabolism by mass action. However, to date there is no evidence that colonic lumen concentrations of SCFAs in patients with quiescent colitis are lower than in a normal person.

The aim of this study was to investigate whether butyrate metabolism is impaired in patients with quiescent colitis. The rate of metabolism of $\left[1-{ }^{13} \mathrm{C}\right]$-butyrate enemas, administered to patients with quiescent colitis, was determined by measuring the rate of production of ${ }^{13} \mathrm{CO}_{2}$ in exhaled breath samples over a four hour time period, and compared with control subjects with no mucosal diseases. In order to compare the rate of production of ${ }^{13} \mathrm{CO}_{2}$ in the two groups, it was imperative that the patient's resting energy expenditure (REE)

Abbreviations used in this paper: BMI, body mass index; REE, resting energy expenditure; RQ, respiratory quotient; SCFA, short chain fatty acids; $\mathrm{VCO}_{2}$, carbon dioxide production. 
Table 1 Patient characteristics

\begin{tabular}{lll}
\hline & Colitis group & Control group \\
\hline Age $(\mathrm{y})$ & $48.9(3.6)$ & $59.9(4.2)$ \\
Mass $(\mathrm{kg})$ & $76.3(4.5)$ & $79.4(3.3)$ \\
BMI $\left(\mathrm{kg} / \mathrm{m}^{2}\right)$ & $25.4(1.1)$ & $26.9(0.9)$ \\
Male:female ratio & $5: 6$ & $8: 2$ \\
\hline
\end{tabular}

was measured concurrently. Differences in the REE between subjects could have a major effect on the rate of metabolism of $\left[1-{ }^{13} \mathrm{C}\right]-$ butyrate and are an important denominator in any comparison between groups.

\section{Materials and methods}

PATIENTS

Eleven adult patients (mean age 48.8 (3.5) years) with quiescent colitis, as assessed by their symptoms and rectal biopsy, and 10 control patients (mean age 59.8 (4.1) years) with no history of inflammatory bowel disease, were recruited from a gastroenterology clinic.

Written consent was obtained from all participants and the study was approved by the University Hospital Ethics Committee.

\section{PROTOCOL}

Three hours prior to investigation a phosphate enema was administered to evacuate the rectum of faeces. A standard light meal (approximately $1674 \mathrm{~kJ}$; percentage energy: protein $20 \%$, fat $25 \%$, carbohydrate $55 \%$ ) was consumed one hour prior to the start of metabolic measurements.

Subjects were rested supine for 15 minutes in a temperature controlled environment $\left(23^{\circ} \mathrm{C}\right)$, prior to measurement of baseline resting energy expenditure (REE), respiratory quotient (RQ), and carbon dioxide production $\left(\mathrm{VCO}_{2}\right)$ using a ventilated hood indirect calorimetry system which has been validated extensively. ${ }^{16}$

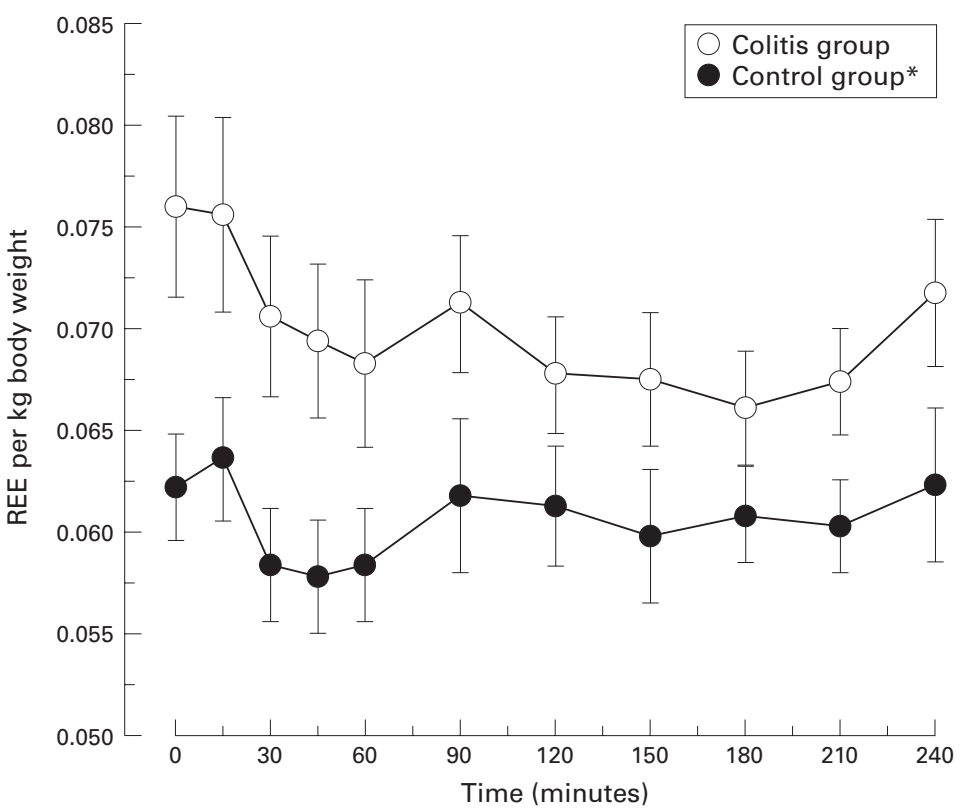

Figure 1 Resting energy expenditure (REE) over the duration of the study in patients with colitis and control subjects. ${ }^{\star} p<0.05$.
For the first eight minutes, subjects were allowed to become accustomed to the hood, then baseline values were determined over the next 12 minutes. At the end of this 20 minute period, a baseline sample of expired breath was collected using a closed system and analysed for background ${ }^{13} \mathrm{CO}_{2}$ enrichment. The collection of expired gas was achieved by the subject exhaling, at the end of a normal inspiratory breath, into a urinary catheter bag which had previously been evacuated. The non-return valve on the bag prevented subsequent dilution of the expired gas with atmospheric air. A Vacutainer needle was inserted through a resealing sampling port and after mixing of the collected gas by gently massaging the bag, triplicate samples were collected into $12 \mathrm{ml}$ glass evacuated tubes with rubber septa (Exetainers, Europa Scientific Ltd). The catheter bag was then opened and the contents expelled. It was flushed twice with room air before being evacuated and resealed in readiness for the next sample collection.

Once baseline values had been obtained, a $100 \mathrm{ml}\left[1-{ }^{13} \mathrm{C}\right]$-butyrate enema, containing $1.25 \mathrm{mmol}\left[1-{ }^{13} \mathrm{C}\right]$-sodium butyrate (Cambrian Gases, Croydon, UK) and $3.75 \mathrm{mmol}$ unlabelled sodium butyrate in $10 \mathrm{mmol}$ sodium chloride solution ( $\mathrm{pH}$ 7.4) was administered. REE, RQ, and $\mathrm{VCO}_{2}$ were measured continuously for the first hour and then for 20 minutes in every 30 minutes for the next three hours. Collections of expired air were made at 15 minute intervals for the first hour and at 30 minute intervals thereafter. Patients were asked to remain still and were not permitted to fall asleep while the 20 minute indirect calorimetry recordings were being made.

${ }^{13} \mathrm{CO}_{2}$ enrichment in the expired breath samples was analysed using an isotope ratio mass spectrometer (20-20 analyser, Europa Scientific Ltd, Crewe, Cheshire, UK). ${ }^{13} \mathrm{CO}_{2}$ enrichment (atom per cent) and $\mathrm{VCO}_{2}$ measurements were used to calculate ${ }^{13} \mathrm{CO}_{2}$ label production rates in $\mu \mathrm{mol} / \mathrm{min}$.

\section{STATISTICS}

The data were analysed using repeated measures analysis of variance (ANOVA), unpaired Student's $t$ test, and comparison of regression coefficients. The primary end point was predefined as the total amount of $\left[1-{ }^{13} \mathrm{C}\right]$-butyrate oxidised to ${ }^{13} \mathrm{CO}_{2}$ and exhaled in four hours. Results are expressed as mean (SEM).

\section{Results}

PATIENT CHARACTERISTICS

Table 1 summarises patient characteristics. The colitis group tended to be younger than the control group, although they were similar in weight and body mass index (BMI). Histopathological assessment of all the rectal biopsy specimens in the colitic group confirmed quiescent colitis and none had local or systemic symptoms of acute disease. These patients were, however, taking a 5-aminosalicylic acid type drug, whereas control patients were taking no medication. 


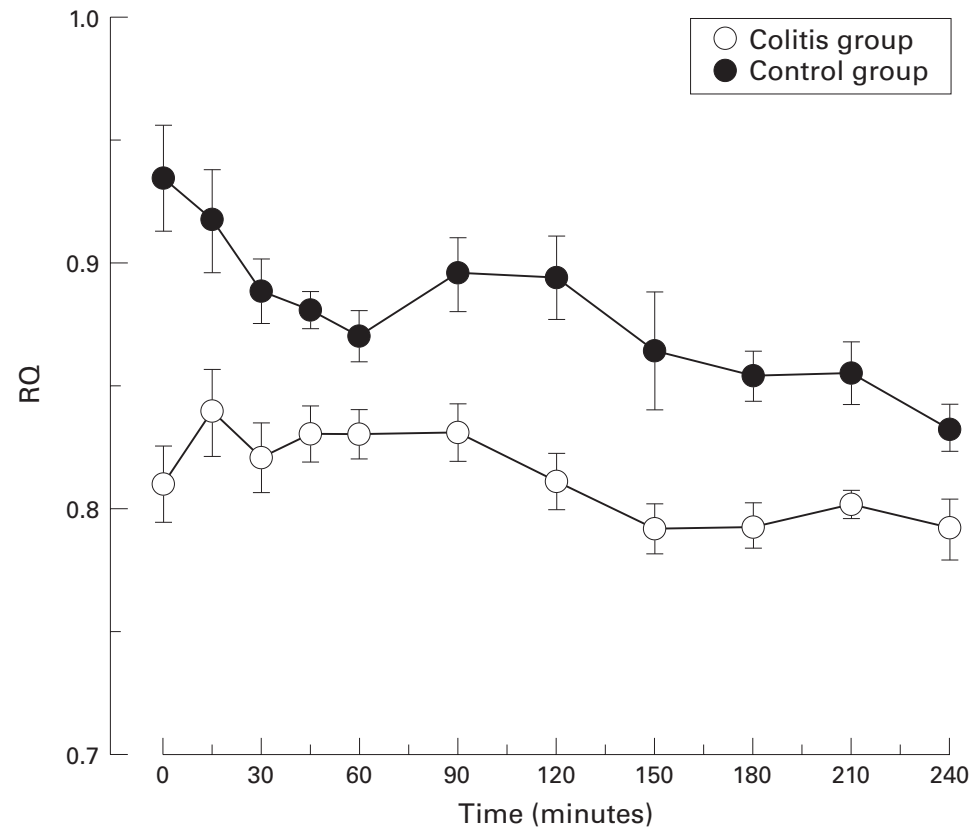

Figure 2 Mean respiratory quotient (RQ) over time in patients with colitis and control subjects. Group $\times$ time, $p<0.001$ (group ANOVA).

Table 2 Production of ${ }^{13} \mathrm{CO}_{2}$ by colitis and control groups

\begin{tabular}{llll}
\hline & Colitis group & Control group & p Value \\
\hline Label production over 240 minutes $(\mu \mathrm{mol})$ & $325(21)$ & $323(17)$ & 0.9 \\
Time to peak production $(\mathrm{min})$ & $108(8)$ & $93(10)$ & 0.2 \\
Peak production per kg body weight $(\mu \mathrm{mol} / \mathrm{min} / \mathrm{kg})$ & $0.023(0.002)$ & $0.026(0.003)$ & 0.3
\end{tabular}

Results expressed as mean (SEM).

METABOLIC RATE

In the control group, the mean REE was stable over the four hours of measurement (baseline 4.94 (0.28), end $5.13(0.44) \mathrm{kJ} / \mathrm{min})$. By contrast, the REE in the colitic group was higher at baseline $(5.78(0.4) \mathrm{kJ} / \mathrm{min})$, but then declined over the next four hours. The REE was expressed per kg body weight to permit comparison between subjects (fig 1) and was

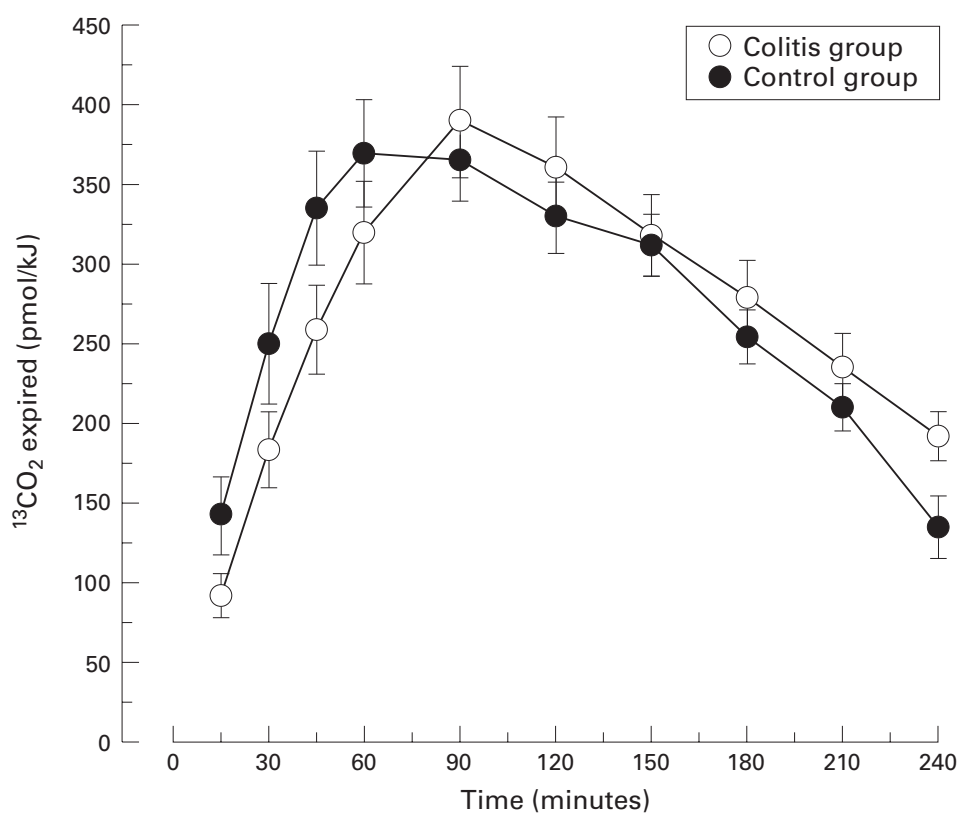

Figure $3{ }^{13} \mathrm{CO}_{2}$ production per $\mathrm{kf}$ of energy expenditure over the time course of the experiment. Group $\times$ time, $p<0.05$ (ANOVA). approximately $20 \%$ higher in the colitic group than the control group at baseline and for the first hour, decreasing to approximately $10 \%$ for the rest of the experiment. This difference was significant $(p<0.05$, group ANOVA).

It is known that REE decreases as age increases; as the colitis group was younger than the control group, this may explain the higher REE in the colitis group. ${ }^{17}$ Indeed, a significant relation was seen between age and REE for both groups $(r=0.69)$ but this disappeared when age was considered as a covariant using repeated measure analysis.

RESPIRATORY QUOTIENT

Mean RQ was calculated by dividing carbon dioxide production by oxygen consumption at each given time point. The RQ of the control group was significantly greater than that of the colitis group at all time points $(p=0.002$, ANOVA; fig 2).

\section{${ }^{13} \mathrm{CO}_{2}$ PRODUCTION}

Prior to administration of the $\left[1-{ }^{13} \mathrm{C}\right]$-butyrate enema the abundance of ${ }^{13} \mathrm{CO}_{2}$ in the expired breath was $1.0836(0.00033)$ atom per cent in the colitis group and $1.0842(0.00025)$ atom per cent in the control group (NS). The quantity of ${ }^{13} \mathrm{CO}_{2}$ expired during the experiment was similar between the two groups $(\mathrm{p}=0.92$; table 2 ) and over the 240 minutes, approximately a quarter of the $1.25 \mathrm{mmol}$ of administered butyrate was recovered in the breath samples of both groups.

There was no significant difference between the two groups when the rate of ${ }^{13} \mathrm{CO}_{2}$ production was standardised for body weight and metabolic rate $(p=0.78$ and $p=0.88$, respectively). However, there was a time $\times$ group interaction with regard to the ${ }^{13} \mathrm{CO}_{2}$ production and it seemed that the control group initially oxidised butyrate faster than the colitic group. Both groups reached similar peak levels of ${ }^{13} \mathrm{CO}_{2}$ production although rate of oxidation in the control group declined faster than in the colitic group ( $p<0.05$, ANOVA). A similar pattern was seen between the two groups when the rate of production of ${ }^{13} \mathrm{CO}_{2}$ was standardised for body weight, BMI, and REE ( $\mathrm{p}<0.05$ and $\mathrm{p}=0.01$, respectively; fig 3 ).

\section{Discussion}

This study has shown that patients with quiescent colitis exhibit no defect in the quantity or the peak rate of production of ${ }^{13} \mathrm{CO}_{2}$ obtained by oxidation of a $\left[1-{ }^{13} \mathrm{C}\right]$-butyrate enema. In vitro studies have suggested a $50 \%$ reduction in the rate of metabolism of butyrate by human colonic epithelial cells and mucosal biopsy tissue from patients with colitis compared with normal patients. ${ }^{8}$ The order of magnitude of the effect seen in vivo is much smaller than in vitro, suggesting that it is highly unlikely that patients with quiescent ulcerative colitis have a primary metabolic defect in the $\beta$ oxidation of butyrate.

These results are similar to those obtained by Den Hond and colleagues ${ }^{18}$ who instilled ${ }^{14} \mathrm{C}$-butyrate enemas into patients with active and quiescent ulcerative colitis. However, in 
their study the REE of the patients undergoing investigation was not controlled for, and so was assumed to be the same. This study found that patients with quiescent ulcerative colitis had a significant greater REE/kg body weight than the control group (fig 1). This difference may be explained as REE declines by about $2 \%$ per decade ${ }^{19}$ and our control group were older than the colitis group. Alternatively, it may be a result of different body composition. The colitic subjects, of which a large proportion were female, had a slightly smaller BMI than the controls. As women have a higher fat content than men for the same BMI, it is likely that the fat content (as a percentage of body weight) was similar between the two groups; thus there would be little difference in standardising REE to $\mathrm{kg}$ body weight or fat free mass. It is unlikely that this difference is a consequence of mucosal inflammation as the patients studied had quiescent colitis based on clinical, endoscopic, and histological criteria. Interestingly the Den Hond group made no allowance for this, despite the ages of their patient groups being significantly different. In this study, patient differences in REE were controlled for when the rate of butyrate oxidation was calculated; results were expressed in $\mu \mathrm{mol} / \mathrm{min}{ }^{13} \mathrm{CO}_{2}$ produced per kJ energy expenditure.

This study has shown a significant, albeit small, difference in the profile of rate of production of ${ }^{13} \mathrm{CO}_{2}$. The colitic group showed a 15-30 minute delay in the time taken to reach maximal ${ }^{13} \mathrm{CO}_{2}$ production and then a slower rate of decline than in the control group. This difference should be interpreted with caution as the group $\times$ time interaction as a determinant of $\left[1-{ }^{13} \mathrm{C}\right]$-butyrate metabolism was not a predefined primary end point. However, this observation may reflect a difference in the rate of absorption of butyrate from the colonic wall, an altered rate of oxidation within the cell, or metabolism at a distant site such as the liver. Our experimental design does not distinguish between these possibilities. The difference is not explained by altered energy expenditures or by the differences observed in respiratory quotients.

Evidence suggests that there is no difference in the rate of rectal absorption of butyrate from dialysis bags in patients with colitis. ${ }^{20}$ However, it may be misleading to extrapolate from this data to suggest that the rate of butyrate absorption into colonocytes is normal, especially as the colonic mucus barrier is thinner and of a different consistency, in patients with colitis. ${ }^{21}$ Structural and motility differences between colitis patients and controls may affect the available surface area and mixing of luminal contents, so altering the kinetics of butyrate absorption and subsequent metabolism. Butyrate is probably transported into the colonocyte by an active transport mechanism; however, nothing is known about variations in the colitic colonocyte. ${ }^{22}$ It is interesting that recent evidence has suggested that there is an inverse correlation between colonic permeability and butyrate oxidation to carbon dioxide ${ }^{18}$ and it may be speculated that active butyrate trans- port is impaired as mucosal inflammation and permeability increase.

Alternatively, this time lag in the overall metabolism of butyrate administered to the left colon may be because colonocytes in patients with quiescent colitis need to induce enzyme systems. However, it has recently been shown that there is no defect in the enzyme systems of the $\beta$ oxidation pathway in the colitic colonocyte and it is difficult to envisage an enzymatic defect which can be overcome within 15-30 minutes. ${ }^{23}$

The other major finding of this study is that the RQ of patients with colitis was significantly lower than that of the control group. Clearly some of this difference may have been due to differences in the composition of the sandwiches consumed one hour before the study commenced. There were no obvious differences in the reported size or composition of this meal, but no formal measurements were made. Furthermore, the effect of this meal will have been waning towards the end of the monitoring period, revealing probable effects of the antecedent diet on the postabsorptive RQ. Thus, the RQ data would be consistent with the combination of the previous meal and the antecedent diet of the colitis group having a higher fat and a lower carbohydrate content than the control group. This may be due to the subjects in the colitis group selecting a low carbohydrate and possibly a low fibre diet in order to avoid provoking abdominal pain or exacerbating their colitis. Alternatively, and intriguingly, it may be that a low fibre diet predisposes patients to the development of colitis and affects relapse rates.

There are no convincing data that patients with mild or quiescent colitis have an altered colonic bacterial population compared with normal patients, nor that there is any difference in luminal concentrations of SCFAs. However, there are formidable methodological problems in ascertaining bacterial populations within the colon and in determining SCFA concentrations at the level of the colonocyte. It is possible to increase the faecal concentration of butyrate by consuming oral corn $\operatorname{starch}^{24}$ or acarbose. ${ }^{25}$ The low fibre diet that patients with colitis consume may lead to altered colonic bacterial populations and lower production of SCFAs, leading to a failure of homoeostasis between the bacteria and the colonocyte, resulting in inflammation.

In conclusion, this study has shown that patients with quiescent ulcerative colitis have no major impairment of butyrate oxidation, even when allowing for potential metabolic differences between groups. However, there was a difference in the time course of utilisation of a butyrate load. It was also found that patients with quiescent colitis have a different $R Q$ to that of control patients, implying that they consume a different diet; however, further studies are needed to clarify this point.

This study was partly funded by a Trent Regional Health Authority Research and Development grant.

1 Cummings JH. Short chain fatty acids in the human colon. Gut 1981;22:763-79. 
2 Chapman MA, Grahn MF, Giamundo P, et al. New technique to measure mucosal metabolism and its use to map substrate utilization in the healthy human large bowel. Br F Surg 1993;80:445-9.

3 Roediger W, Rae DA. Trophic effect of short chain fatty acids on mucosal handling of ions by the defunctioned colon. Br f Surg 1982;69:23-5.

4 Harig JM, Soergel KH, Komorowski RA, et al. Treatment of diversion colitis with short-chain-fatty acid irrigation. $N$ Engl f Med 1989;320:23-8.

5 Roediger WE. Role of anaerobic bacteria in the metabolic welfare of the colonic mucosa in man. Gut 1980;21:793-8.

6 Roediger WE. The colonic epithelium in ulcerative colitis: an energy-deficiency disease? Lancet 1980;ii:712-15.

7 Roediger W, Nance S. Metabolic induction of experimental ulcerative colitis by inhibition of fatty acid oxidation. $\mathrm{Br} \mathcal{F}$ Exp Pathol 1986;67:773-82.

8 Chapman MA, Grahn MF, Boyle MA, et al. Butyrate oxidation is impaired in the colonic mucosa of sufferers of quiestion is impaired in the colonic mucosa of

9 Chapman MA, Grahn MF, Hutton M, et al. Butyrate metabolism in the terminal ileal mucosa of patients with metabolism in the terminal ileal mucosa
ulcerative colitis. Br 7 Surg 1995;82:36-8.

10 Finnie IA, Taylor BA, Rhodes JM. Ileal and colonic epithelial metabolism in quiescent ulcerative colitis: increased glutamine metabolism in distal colon but no defect in butyrate metabolism. Gut 1993;34:1552-8.

11 Clausen MR, Mortensen PB. Kinetic studies on colonocyte metabolism of short chain fatty acids and glucose in ulcerative colitis. Gut 1995;37:684-9.

12 Scheppach W, Sommer H, Kirchner T, et al. Effect of butyrate enemas on the colonic mucosa in distal ulcerative colitis. Gastroenterology 1992;103:51-6.

13 Steinhart AH, Hiruki T, Brzezinski A, et al. Treatment of left-sided ulcerative colitis with butyrate enemas: a controlled trial. Aliment Pharmacol Ther 1996;10:729-36.

14 Patz J, Jacobsohn WZ, Gottschalk-Sabag S, et al. Treatment of refractory distal ulcerative colitis with short chain fatty acid enemas. Am $\mathcal{F}$ Gastroenterol 1996;91:731-4.
15 Scheppach W. Treatment of distal ulcerative colitis with short-chain fatty acid enemas. A placebo-controlled trial. German-Austrian SCFA Study Group. Dig Dis Sci 1996;41:2254-9.

16 Fellows IL, Macdonald IA. An automated method for the measurement of oxygen consumption and carbon dioxide excretion in man. Clin Phys Physiol Meas 1985;6:349-55.

17 Fukagawa NK, Bandini LG, Young JB. Effect of age on body composition and resting metabolic rate. Am f Physiol 1990;259:E233-8.

18 Den Hond E, Hiele M, Evenepoel P, et al. In vivo colonic butyrate metabolism and colonic permeability in extensive ulcerative colitis. Gastroenterology 1998;115:584-90.

19 Elia M. Energy expenditure in the whole body. In: Kenny $\mathrm{JM}$, Tucker HN, eds. Energy metabolism: tissue determinants and cellular corollaries. New York: Raven Press Ltd, 1992:19-59.

20 Hove H, Holtug K, Jeppesen PB, et al. Butyrate absorption and lactate secretion in ulcerative colitis. Dis Colon Rectum 1995;38:519-25.

21 Corfield AP, do Amaral Corfield C, Wagner SA, et al. Loss of sulphate in human colonic mucins during ulcerative colitis. Biochem Soc Trans 1992;20:95S

22 Mascolo N, Rajendran VM, Binder HJ. Mechanism of short-chain fatty acid uptake by apical membrane vesicles of rat distal colon. Gastroenterology 1991;101:331-8.

23 Allan ES, Winter S, Light AM, et al. Mucosal enzyme activity for butyrate oxidation; no defect in patients with ulcerative colitis. Gut 1996;38:886-93.

24 Weaver GA, Krause JA, Miller TL, et al. Cornstarch fermentation by the colonic microbial community yields more butyrate than does cabbage fiber fermentation; cornstarch fermentation rates correlate negatively with methanogenesis. Am F Clin Nutr 1992;55:70-7.

25 Weaver GA, Tangel CT, Krause JA, et al. Acarbose enhances human colonic butyrate production. $\mathcal{F}$ Nutr 1997;127:71723. 